\title{
Tensile behaviour of carbon fabric reinforced cementitious matrix composites as both strengthening and anode materials
}

Dol:

10.1016/j.compstruct.2019.111675

\section{Document Version}

Accepted author manuscript

Link to publication record in Manchester Research Explorer

Citation for published version (APA):

Wei, L., Zhu, J., Ueda, T., Su, M., Liu, J., Liu, W., Tang, L., \& Xing, F. (2019). Tensile behaviour of carbon fabric reinforced cementitious matrix composites as both strengthening and anode materials. Composite Structures, 234, 111675. https://doi.org/10.1016/j.compstruct.2019.111675

Published in:

Composite Structures

\section{Citing this paper}

Please note that where the full-text provided on Manchester Research Explorer is the Author Accepted Manuscript or Proof version this may differ from the final Published version. If citing, it is advised that you check and use the publisher's definitive version.

\section{General rights}

Copyright and moral rights for the publications made accessible in the Research Explorer are retained by the authors and/or other copyright owners and it is a condition of accessing publications that users recognise and abide by the legal requirements associated with these rights.

\section{Takedown policy}

If you believe that this document breaches copyright please refer to the University of Manchester's Takedown Procedures [http://man.ac.uk/04Y6Bo] or contact uml.scholarlycommunications@manchester.ac.uk providing relevant details, so we can investigate your claim.

\section{OPEN ACCESS}


Liangliang Wei, Ji-Hua Zhu, Tamon Ueda, Meini Su, Jun Liu, Wei Liu, Luping Tang, Feng Xing, (2020), "Tensile behaviour of carbon fabric reinforced cementitious matrix composites as both strengthening and anode materials", Composite Structures, 234:111675.

1 Tensile behaviour of carbon fabric reinforced cementitious matrix composites as both strengthening and anode materials Liang-Liang Wei a, b, Ji-Hua Zhu ${ }^{\text {a, }}{ }^{*}$, Tamon Ueda ${ }^{\text {b }}$, Mei-Ni Su ${ }^{\text {c, Jun Liu }}{ }^{\text {a }}$, Wei Liu ${ }^{\text {a }}$, Lu-Ping Tang ${ }^{\mathrm{d}}$, Feng Xing ${ }^{\mathrm{a}}$

$5 \quad{ }^{a}$ Guangdong Province Key Laboratory of Durability for Marine Civil Engineering, School of Civil

6 Engineering, Shenzhen University, Shenzhen 518060, Guangdong, China

$7 \quad{ }^{b}$ Laboratory of Engineering for Maintenance System, Faculty of Engineering, Hokkaido University,

8 Sapporo 060-8628, Japan

$9{ }^{\mathrm{c}}$ School of Mechanical, Aerospace and Civil Engineering. University of Manchester, Manchester

10 M1 7JR, UK

$11{ }^{\mathrm{d}}$ Department of Civil and Environmental Engineering, Chalmers University of Technology,

12 Gothenburg SE-412 96, Sweden

$13 \quad{ }^{*}$ Corresponding author: zhujh@szu.edu.cn (J.H. Zhu)

Tel./Fax: +86-755-2653-4021

E-mail address: weiliangliang@email.szu.edu.cn (L.L. Wei), ueda@eng.hokudai.ac.jp (T. Ueda), meini.su@manchester.ac.uk (M.N. Su), liujun@szu.edu.cn (J. Liu), liuwei@szu.edu.cn (W. Liu), tang.luping@chalmers.se (L.P. Tang), xingf@szu.edu.cn (F. Xing).

\section{Abstract}

Recently, a promising solution to corroded steel reinforced concrete structures was proposed in which a dual-functional carbon-fabric reinforced cementitious matrix (carbon-FRCM) composite is used for 
impressed current cathodic protection (ICCP) and structural strengthening (SS); this method is referred to as ICCP-SS. The tensile behaviour of carbon-FRCM must be understood for design purposes. In this study, the tensile characteristics of carbon-FRCM composites with different fabric reinforcement ratios were assessed to determine the strengthening capability of the materials. Then, using the composite as an anode material, the tensile behaviour of carbon-FRCM specimens subjected to anodic polarization in ICCP was evaluated. Direct tensile tests were conducted to obtain the tensile stressstrain behaviour of the carbon-FRCM specimens. By comparing the results from each case, the influences of different parameters on the tensile behaviour of the carbon-FRCM composites were evaluated, and useful information regarding the application of these materials in ICCP-SS was obtained.

Keywords: FRCM composites; tensile behaviour; cathodic protection; anode material.

\section{Introduction}

A promising fabric reinforced cementitious matrix (FRCM) composite composed of fibres in a fabric mesh shape and an inorganic matrix has been investigated for strengthening masonry and/or reinforced concrete (RC) structures [1-5]. Textile reinforced mortar (TRM) and textile reinforced concrete (TRC) are in the same composite family as FRCM. Unlike the well-known fibre reinforced polymer (FRP) composite, the fabric mesh in an FRCM is typically made of fibres that are individually coated but are not bonded together by a polymeric resin; i.e., FRCMs use "dry fibres" [6]. Compared to an FRP using an organic polymeric resin, an inorganic matrix has better inherent heat resistance, superior compatibility with the substrate and greater long-term durability. These properties have driven 
researchers who work mainly on the intervention of existing structures to conduct systematic investigations on the strengthening performance of FRCM composites.

Several studies [7-11] have been conducted on the mechanical characterization of FRCMs combining various types of fabrics, such as carbon, glass, polybenzoxazole (PBO), and basalt fabrics, with different inorganic matrices (cement-based, geo-polymer, lime-based mortar). Arboleda et al. [12] compared the tensile behaviours of PBO-FRCM, carbon-FRCM and glass-FRCM using both clamping grip and clevis grip methods. Their results showed that the stress-strain behaviour was trilinear when using the clamping grip method, whereas the stress-strain behaviour was bilinear when using the clevis grip method. Donnini et al. [13] performed tensile tests with the clevis grip method by changing the bonded length of the metallic tabs used to grip the ends of the specimens. They concluded that a bonded length of $150 \mathrm{~mm}$ was suitable for characterizing FRCM composites. The performance and failure modes of FRCMs reinforced with multiple carbon fabric plies were also investigated by Donnini et al. [13]. The tested carbon fabric was coated with epoxy resin and quartz sand in combination with lime-based mortar. Lime-based matrices are generally used for strengthening masonry structures, while cement-based mortar is suitable for strengthening RC structures [7]. Barhum et al. [14] addressed the influence of the dispersing short glass and carbon fibres in cement-based mortar on the tensile behaviour of TRC and the bonding behaviour between yarn and mortar matrix.

60 In their study, the TRC was reinforced by an alkali-resistant (AR) glass fabric with a polymer coating,

61 and improvements in both the tensile strength of the TRC and the bond strength between the yarn and the matrix were achieved. However, a limited number of studies have been performed on carbonFRCM composites with multiple layers of dry fabric reinforcement and mortar matrix modified by 
short, dispersed carbon fibres.

FRCM strengthening is a potential method for rehabilitating and upgrading aged RC structures [15-18]. Babaeidarabad et al. [19] investigated the feasibility of using FRCMs for strengthening RC members, and they considered the effect of multiple layers of dry fibre fabric in FRCMs. Yin et al. [20] investigated the compressive performance of TRC-strengthened concrete columns containing steel reinforcement with chloride-induced corrosion. The load-bearing capacity and ductility of RC columns increased with an increasing number of textile layers; however, both the load-bearing capacity and the ductility decreased after chloride wet-dry cycling due to the corrosion effect of chloride ions. It is expected that the load-bearing capacity of FRCM-strengthened RC structures could be continuously reduced from the persistent chloride-induced corrosion of the steel reinforcement in the concrete. Impressed current cathodic protection (ICCP) has been shown to be one of the most efficient methods for addressing the chloride-induced corrosion of steels in concrete [21,22]. Therefore, Zhu et al. $[23,24]$ proposed a promising solution (ICCP-SS) to increase the load-bearing capacity of aged RC structures and to control the corrosion of steels in concrete by using a dualfunctional carbon-FRCM composite. The ICCP technique is compatible with structural strengthening (SS) when using carbon-FRCM, which serves as the anode material for the ICCP and as a strengthening material in SS; the combined approach forms the ICCP-SS intervention system.

The mechanical and anodic performance of the dual-functional carbon-FRCM composites are essential to the ICCP-SS intervention system. Nguyen et al. [25] investigated the performance of carbon fibre fabric as an ICCP anode in saturated calcium hydroxyl solution $\left(\mathrm{Ca}(\mathrm{OH})_{2}\right)$. They reported that the weight loss of the carbon fabric after anodic polarization in ICCP was $2.69 \%$. Hence, it is 
necessary to understand the durability of anode materials in ICCP. However, studies have not yet clarified the durability issues of carbon-FRCMs, such as the degradation in the tensile behaviour and anodic performance of the materials, due to the influence of anodic polarization in ICCP. In this paper, 21 tensile tests using the clevis grip method were conducted in two series. For the first series, 9 tensile tests were performed on carbon-FRCM specimens reinforced with 1, 2, and 4 carbon fabric layers (three specimens for each configuration) to investigate the influence of the fabric reinforcement ratio on the tensile behaviour. For the second series, carbon-FRCM specimens reinforced with 2 layers of carbon fabric mesh were used as anode materials in an ICCP procedure.

Then, 12 tensile tests (four anodic polarization cases and three specimens for each case) were conducted on carbon-FRCM specimens to investigate the influence of anodic polarization in ICCP.

\section{Experimental programme}

\subsection{Materials}

\subsubsection{Cement-based mortar matrix}

A cement-based mortar matrix composition for carbon-FRCM composites is shown in Table 1.

The binder was Portland cement type 52.5 R, and the water-to-cement ratio was 0.35 . Quartz sand with different particle sizes was used; the fine size ranged from $0.1 \mathrm{~mm}$ to $0.5 \mathrm{~mm}$, and the moderate size was smaller than $1.0 \mathrm{~mm}$. The weight ratio between fine and moderate sand was 0.5 . The mortar contained 0.75 wt. $\%$ (measured as a percent of the cement weight) short, dispersed carbon fibres with a nominal length of $3 \mathrm{~mm}$ and a diameter of $7 \mu \mathrm{m}$. Adequate workability was obtained using a small amount of superplasticizer. The measured average flexural strength and compressive strength of the 

in accordance with BS EN 196 [26].

\subsubsection{Carbon fabric mesh}

Fig. 1 shows the unbalanced carbon fabric mesh used to create the carbon-FRCM composites, in

which the bundle density in the primary and secondary directions is 100 and $130 \mathrm{~m}^{-1}$, respectively.

The nominal number of filaments of one bundle carbon fibre in both directions is 12 thousand, and each filament has a nominal diameter of $7 \mu \mathrm{m}$. Table 2 gives the tensile properties of the carbon fibre filament obtained from the manufacturer and the measured tensile properties of a dry carbon fibre bundle in which the fibre filaments are individually coated but are not bonded. Specimen preparation and testing were conducted in accordance with ASTM D 4018 [27].

\subsection{Preparation of carbon-FRCM panels} panels. All panels were squares with side lengths of $650 \mathrm{~mm}$. The panel thickness depended on the number of layers of carbon fabric mesh: $10 \mathrm{~mm}$ for one layer, $15 \mathrm{~mm}$ for two layers and $25 \mathrm{~mm}$ for four layers. The fabric reinforcement ratio $\left(\rho_{c f m}\right)$ was the cross-sectional area of the carbon fabric mesh $\left(A_{c f m}\right)$ in the carbon-FRCM divided by the cross-sectional area of the composite matrix $\left(A_{F R C M}\right)$, as shown in Eq. (1). The fabric reinforcement ratios for one, two and four layers of carbon-FRCM were $0.462 \%, 0.615 \%$ and $0.739 \%$, respectively. The preparation of carbon-FRCM panels with two layers of carbon fabric mesh is shown in Fig. 2.

$$
\rho_{c f m}=A_{c f m} / A_{F R C M}
$$


reinforcement ratio, were cut as described in section 2.4. Four panels in series II were used for anodic polarization in the ICCP procedure, as described in section 2.3, and the preparation of the carbonFRCM coupons for the tensile tests is described in section 2.4.

\subsection{ICCP procedure}

In series II, we focused on the evolution of the tensile behaviour of the carbon-FRCM composites after a specified level of anodic polarization in ICCP. It was not possible to conduct direct tensile tests of the carbon-FRCM composites after bonding to concrete; therefore, the composites were subjected to a simulated ICCP procedure prior to direct tensile testing.

Fig. 3 shows a setup for the carbon-FRCM composite used as the anode material for achieving ICCP. First, six deformed steel rebars with diameters of $12 \mathrm{~mm}$, which were placed at intervals of 100 $\mathrm{mm}$, were fixed at the vertical centre of the wooden mould. Next, the mould with steel rebars was placed at the surface of the carbon-FRCM panel. The longitudinal direction of the rebars was parallel to the primary direction of the carbon fibre bundles. All joints were bonded and blocked off with a silica gel. All sides in the thickness of the carbon-FRCM panels were coated with a polymeric resin. Subsequently, saturated $\mathrm{Ca}(\mathrm{OH})_{2}$ solution was added into the mould, filling more than $80 \%$ of the mould volume. In the simulated ICCP setup, the saturated $\mathrm{Ca}(\mathrm{OH})_{2}$ solution assumed the role of the concrete, the steel rebars soaking in the solution served as the object requiring protection in the concrete, and the carbon-FRCM composite acted as the anode material. Finally, the steel rebars were chained together and connected to the negative terminal of a direct current (DC) power supply, while the top layer of the carbon fabric mesh close to the solution was connected to the positive terminal of the DC power supply. Stainless steel strips were used to form an electrically conductive pathway 
147 between the carbon fabric bundles in the primary and secondary directions at the top layer. In addition,

148 the steel rebars in the mould were kept submerged by adding saturated $\mathrm{Ca}(\mathrm{OH})_{2}$ solution to counteract

149 the evaporation of water.

150 Four different current densities (i.e., the anodic current density $\left(i_{a}\right)$, which is calculated with Eq.

151 (2)) were considered for the carbon fabric mesh during the ICCP procedure. The area of carbon fabric

mesh $\left(A_{a}\right)$ is defined as the geometric surface area of carbon fiber bundles in the two sides of one layer

of carbon fabric mesh embedded in the mortar matrix. Through the analysis of image processing, the

percentage of the geometric surface area of carbon fiber bundles in the one side is approximately $57.6 \%$

were $51.9 \mathrm{~mA}, 155.7 \mathrm{~mA}, 207.6 \mathrm{~mA}$, and $311.4 \mathrm{~mA}$, which correspond to anodic current densities of

$125 \mathrm{~mA} / \mathrm{m}^{2}, 375 \mathrm{~mA} / \mathrm{m}^{2}, 500 \mathrm{~mA} / \mathrm{m}^{2}$, and $750 \mathrm{~mA} / \mathrm{m}^{2}$, respectively.

$$
i_{a}=I / A_{a}
$$

During the ICCP procedure, the cell voltages between the carbon fabric mesh and the steel rebars

were recorded using a digital datalogger. In addition, the instant-off potentials of the steel rebars and

$$
q=i_{a} \times t
$$




\subsection{Preparation of carbon-FRCM coupons for the tensile tests}

The dimensions of the carbon-FRCM coupons used for the direct tensile tests were set in accordance with ICC-ES AC434 [28]. First, a 25-mm strip around the edge of each carbon-FRCM panel $(650 \mathrm{~mm} \times 650 \mathrm{~mm})$ should be removed with a cutting machine. Subsequently, six carbonFRCM coupons with a nominal dimension of $600 \mathrm{~mm} \times 100 \mathrm{~mm}$ were obtained from the trimmed panel $(600 \mathrm{~mm} \times 600 \mathrm{~mm})$. Next, metallic tabs with a thickness of $2 \mathrm{~mm}$ and a bond length of 200 mm were bonded to the ends of the carbon-FRCM coupons with polymeric resin. The middle region of the coupons, which was $200 \mathrm{~mm}$ in length, was tested. Finally, the carbon-FRCM coupons with metallic tabs, as shown in Fig. 4(a), can be used to conduct tensile tests after the resin solidifies for at least 48 hours.

Table 3 gives the overall test parameters of the carbon-FRCM coupons used in the tensile tests. In series I, the carbon-FRCM coupons were named L (layer), followed by the number of layers of carbon fabric mesh. In series II, the coupons were denoted L2 (two layers of carbon fabric mesh)-AP (anodic polarization)-i (current density) followed by the value of applied current density during the ICCP procedure. Based on the monitored cell voltages and instant-off potentials, the current density of $125 \mathrm{~mA} / \mathrm{m}^{2}$ ran constantly for 62 days, and the specified current densities of 375 and $500 \mathrm{~mA} / \mathrm{m}^{2}$ ran for 34 days; the latter current densities were then adjusted to $125 \mathrm{~mA} / \mathrm{m}^{2}$ for 24 days. The specified current density of $750 \mathrm{~mA} / \mathrm{m}^{2}$ ran for 23 days, which was reduced to $125 \mathrm{~mA} / \mathrm{m}^{2}$ for 17 days and then further reduced to $62.5 \mathrm{~mA} / \mathrm{m}^{2}$ for 14 days. The accumulated charge densities in each current density scenario were calculated with Eq. (3); the results are shown in Table 3.

\subsection{Direct tensile tests}


ES AC434 [28] was adopted, in which clevis grips were used to connect the coupons and the loading

The global deformation measurements permitted us to account for all the cracks developed along the carbon-FRCM coupons.

\section{Results and discussion in series I}

\subsection{Results overview}

Fig. 5(a) shows the stress-strain behaviour of the carbon-FRCM coupons regarding the overall cross-sectional area of the carbon fabric mesh. The stress in the vertical axis of the carbon-FRCM coupon was calculated with Eq. (4), in which the tensile force $(F)$ was divided by the nominal crosssectional area of the carbon fibre mesh $\left(A_{c f m}\right)$. The strain in the horizontal axis of the carbon-FRCM was the deformation measured within the 200 -mm gauge length of the extensometer.

$$
\sigma_{c f}=F / A_{c f m}
$$

As expected, the tensile behaviour of the carbon-FRCM composites was characterized by three stages in all specimens. Fig. 6 shows a typical stress-strain relation of the FRCM composites. The first stage, i.e., the uncracked stage $(\mathrm{OA})$ is characterized by linear behaviour, and this stage ends with the formation of the first crack in the mortar matrix. The average strain at the end of the uncracked stage 

with respect to the tensile strength of the dry carbon fibre bundle $\left(f_{c f b}=2125 \mathrm{MPa}\right)$, as shown in Eq.

212 (5). The utilization efficiency increased to $36.5 \%$ at the end of the uncracked stage. The stiffness values

213 of the L1, L2, and L4 specimens in the uncracked stage were $4557 \mathrm{GPa}, 5656 \mathrm{GPa}$ and $4619 \mathrm{GPa}$, 214 respectively. These figures were considerably higher than the elastic modulus of carbon fibre ( $E_{c f}=$ 215 196.4 GPa). This high initial stiffness illustrates the advantage of FRCM over FRP.

After the first crack, during the second stage (crack development stage (AB)), the composite exhibited nonlinear behaviour with both a sudden reduction in stiffness and multiple cracks occurring in the mortar matrix. The stress in the carbon-FRCM dropped instantaneously several times as new cracks formed. The cracks propagated across the carbon fabric mesh and widened as the load increased. The crack development stage finished when the cracks in the mortar matrix caused by tension were saturated.

The third stage is the cracked stage (BC) in which the carbon fabric mesh governed the tensile behaviour of the carbon-FRCM composite, and the contribution of the mortar matrix was limited but nonnegligible. The width of the cracks increased as the applied load increased, and one of the cracks became the major crack that controlled the failure. The maximum load reached at the end of the third stage caused the failure of the carbon-FRCM composites; the failure was a result of sudden crack widening, which led to a distinct slippage of continuous carbon fibre bundles within the mortar matrix, as shown in Fig. 7. The average maximum tensile strength was $1474 \mathrm{MPa}$ in the L1 specimens, 1630 MPa in the L2 specimens and $1303 \mathrm{MPa}$ in the L4 specimens; the corresponding utilization efficiency 
carbon fibre bundle, respectively. The average stiffness in the cracked stage, which was 92.4 GPa in the L1 specimens, 77.3 GPa in the L2 specimens and 69.0 GPa in the L4 specimens, decreased as the

fabric reinforcement ratio increased. Comparing to the tensile strength and tensile elastic modulus of

dry carbon fiber bundles (i.e. $f_{c f b}=2125 \mathrm{MPa}, E_{c f}=196.4 \mathrm{GPa}$ ), the maximum tensile strength and

cracked tensile elastic modulus of carbon-FRCM (i.e. $\sigma_{u}=1630 \mathrm{MPa}, E_{p o s t-c r}=77.3 \mathrm{GPa}$ ) with two

layers of carbon fabric mesh was lower. The possible explanation is the difference of tensile failure

between dry carbon fiber bundles and carbon-FRCM composite material. The tensile failure of carbon

fiber bundles was almost rupture of carbon fibers, while the tensile failure of carbon-FRCM was the

slippage of carbon fiber bundles within the mortar matrix. In addition, there were ten carbon fiber

bundles in each layer of carbon fabric mesh in carbon-FRCM composite that possibly results in an

explain that the tensile strength and cracked tensile elastic modulus of carbon-FRCM composite was place due to the further slippage of the carbon fibres within the bundles.

$$
\delta_{c f}=f_{c f_{-} t e s t} / f_{c f b}
$$

The tensile behaviour of the carbon-FRCM was complicated due to a complex microstructural 
cracked states. Regarding the design of the strengthening system using carbon-FRCM as a composite material, both strength and stiffness should be evaluated by considering the entire area of the composite, including the matrix and fabric reinforcement; the stress and total cross-sectional area of the carbon-FRCM can be calculated by Eqs. (6) and (7), respectively. Fig. 5(b) shows the stress-strain behaviour of carbon-FRCM regarding the entire cross-sectional area of the composite. The trend was the same as that shown in Fig. 5(a); however, the values of the tensile stress of the composite depicted on the vertical axis are different in the two figures. The following discussion of the influence of the fabric reinforcement ratio on the mechanical behaviour of carbon-FRCM was performed on the basis of the stress-strain relationship shown in Fig. 5(b).

Here, $\sigma_{F R C M}$ is the stress in the carbon-FRCM with respect to the total cross-sectional area of the

FRCM composite, $F$ is the tensile force applied to the carbon-FRCM, $A_{F R C M}$ is the total cross-sectional area of the carbon-FRCM composite, $b_{F R C M}$ is the width of the carbon-FRCM, and $t_{F R C M}$ is the thickness of the carbon-FRCM.

\subsection{Discussion of the fabric reinforcement ratio}

Fig. 8 shows the critical points in the stress-strain curve of the carbon-FRCM composites regarding the entire cross-sectional area of the composite, where the points are the average values

270 from the three repeated specimens shown in Fig. 5(b). The critical points at $60 \%, 90 \%$ and $100 \%$ of

271 the ultimate stress in the third stage are shown in Fig. 8(a). According to ICC-ES AC434 [28], the tensile modulus of elasticity in the third stage can be determined with Eq. (8). In addition, the critical 
273 points at the formation of each crack in the second stage are shown in Fig. 8(b). Table 4 summarizes

274 the tensile testing results of the carbon-FRCM composites, in which the tensile stress and tensile elastic

275 modulus before and after cracking were calculated with Eqs. (4), (6) and (8), respectively.

$$
E_{f}=\frac{0.9 \sigma_{u}-0.6 \sigma_{u}}{\varepsilon_{® 0.9 \sigma_{u}}-\varepsilon_{@ 0.6 \sigma_{u}}}
$$

\subsubsection{Strength and stiffness of the carbon-FRCM composites}

It is evident that the stress-strain behaviours of the L2 and L4 specimens were almost identical but different from the stress-strain behaviour of the L1 specimens (see Fig. 8(a)). In the first stage, the average stress of each carbon-FRCM composite at cracking ranged from 3.59 MPa to 4.34 MPa, which was close to the tensile strength of the mortar matrix. This finding demonstrated that the cracking load of the carbon-FRCM composites mainly depended on the mechanical properties of the matrix material. The stress at the formation of the first crack in the L2 and L4 specimens was slightly higher than that in the L1 specimens because there were more cross-links between the short, dispersed carbon fibres in the mortar matrix and continuous carbon fabric mesh reinforcement [14]. The stiffness of the carbon-FRCM composites at the cracked stage increased from $0.42 \mathrm{GPa}$ at a fabric reinforcement ratio of $0.462 \%(\mathrm{~L} 1)$ to $0.59 \mathrm{GPa}$ and $0.51 \mathrm{GPa}$ at fabric reinforcement ratios of $0.615 \%$ (L2) and $0.739 \%$ (L4), respectively.

The average ultimate tensile strengths of the L2 and L4 specimens were $10.03 \mathrm{MPa}$ and 9.62 MPa, which were $47.3 \%$ and $41.3 \%$ higher than that of the L1 specimens. The average stiffness of the L1 specimens at the cracked stage was also slightly less than that of the L2 and L4 specimens. Donnini et al. [13] also confirmed the identical results regarding the effect of number of layers of fabric mesh 

matrix. The cement-based mortar matrix cannot fully penetrate the dry fibre bundle. Häußler-Combe et al. [29] proposed a mechanical model that segments the total number of filaments in a fibre bundle embedded in a cement matrix into two parts: outer filaments and central filaments. The outer filaments are fully bonded with the matrix, whereas the central filaments of a bundle have no connection to the matrix but contact neighbour filaments. It is reasonable that the cracking of the mortar matrix caused the brittle failure of a partial volume of outer filaments in the L1 specimens, activating the friction and bonding among the central filaments. The loss of bonding around the outer filaments and the activation of friction between the central filaments led to substantial slippage of the fibre bundle within the matrix. The numerical modelling results indicated that the deficiency of premature filament failure and the section 3.2.2.

\subsubsection{Crack propagation}

For the $\mathrm{L} 1$ specimens, a drastic decrease in the tensile stress from $3.58 \mathrm{MPa}$ to $1.83 \mathrm{MPa}$ was observed after the formation of the first crack in the mortar; the drop was less substantial in the L2 and L4 specimens, as shown in Fig. 8(b). Moreover, the average cracking strain in the L1 specimens was $0.02 \%$, and the strain increased to $0.13 \%$ after the first crack. The average strains were $0.03 \%$ and $0.015 \%$ for the L2 and L4 specimens, respectively, after the first crack. This strain increase was 
transition from the uncracked to the cracked state is that the fracture energy had to be released when the mortar cracked during tensile loading. The roles of the carbon fabric mesh in the FRCM composites were not only to bear the load transferred from the mortar but also to absorb the fracture energy as the mortar cracked. Increasing the fabric reinforcement ratio by increasing the number of fabric mesh layers enhances the ability of the composite to absorb the fracture energy.

\section{Results and discussion in series II}

\subsection{Results of the ICCP procedure}

Fig. 9 shows the results of the feeding voltage $\left(E_{\text {feed }}\right)$ between the carbon-FRCM anode and the steel cathode, the anode potential $\left(E_{a n}\right)$, and the steel potential $\left(E_{c a t}\right)$ as a function of the testing time.

The instant-off steel potentials $\left(E_{c a t}\right)$ in all specimens were more negative than $-800 \mathrm{mV}$ with respect to the $\mathrm{Ag} / \mathrm{AgCl} \mathrm{RE}$. According to $\mathrm{BS} \mathrm{EN} 12696-2000$ [30], the results of $E_{c a t}$ in the present paper meet the criteria for successful protection of steels in concrete, which indicates the efficiency of ICCP using carbon-FRCM as an anode material. A constant current density of $125 \mathrm{~mA} / \mathrm{m}^{2}$ was applied continuously in the L2-AP-i125 specimen, in which both $E_{\text {feed }}$ and $E_{a n}$ increased gradually as the testing time increased. The feeding voltage in the L2-AP-i125 specimen started at $1.74 \mathrm{~V}$ and ended at $8.30 \mathrm{~V}$. Compared with the results of the L2-AP-i125 specimen, a higher rate of increase in the feeding voltage was found in the L2-AP-i375, L2-AP-i500 and L2-AP-i750 specimens during the first month (see Fig. 9(b)-(d)). Although the current density was subsequently reduced to $125 \mathrm{~mA} / \mathrm{m}^{2}$ in the L2-AP-i375, L2-AP-i500 and L2-AP-i750 specimens, the increasing rate in the feeding voltage did not slow in these specimens. It is possible that some deterioration could have occurred in the carbon-FRCM composites. 

section of the carbon-FRCM composites subjected to a current density of $375 \mathrm{~mA} / \mathrm{m}^{2}$ was sprayed with a phenolphthalein indicator to investigate the causes of deterioration. Visual acidification was other specimens subjected to anodic polarization in the ICCP procedure. This phenomenon can be explained by the anodic reactions occurring at the interface between the carbon fibres and the mortar matrix, as shown in Eq. (9) [31]. In these zones, the conductive cement-based mortar matrix and carbon fibre bundle appeared to be damaged (see Fig. 10), which could result in the loss of electrical continuity between them; hence, the increasing feeding voltage could be caused by the loss of electrical continuity [31]. Thus, the feeding voltage can be assumed as an implicit parameter to evaluate the damage of the carbon-FRCM anode.

\subsection{Overview of the tensile test results}

Fig. 11 shows the stress-strain behaviour of the carbon-FRCM composites subjected to anodic polarization in the ICCP procedure; note that the stress-strain behaviour of the L2 specimen is also shown in this figure as a reference. All specimens showed bilinear behaviour. However, the anodic polarization had a significant difference on the tensile performance of the samples, including the ultimate tensile strength and strain and the stiffness at the cracked stage. The tensile strength and strain decreased when the carbon-FRCM was subjected to anodic polarization in the ICCP procedure. The 

significant progressive drop in the tensile stress after the peak strength was observed in the L2-APi125, L2-AP-i375, L2-AP-i500 and L2-AP-i750 specimens; however, the failure mode was the slippage of the carbon fibre bundle within the mortar matrix, as in the case without anodic polarization, as shown in Fig. 6.

4.3 Mechanical properties of the carbon-FRCM composites subjected to anodic polarization in the

\section{ICCP procedure}

The tensile test results of all specimens are presented in Table 4. Fig. 12(a) shows the effect of

current density on the tensile strength of the test specimens. The vertical axis of this figure shows the percentage of tensile strength retained after anodic polarization, which is a ratio of the maximum tensile stress of the test specimens subjected to anodic polarization to the tensile strength of the L2 specimen. A significant reduction was found in the L2-AP-i125 and L2-AP-i375 specimens, where $75.0 \%$ and $49.9 \%$ of the tensile strength was retained, respectively. When the current density was increased to 500 and $750 \mathrm{~mA} / \mathrm{m}^{2}$, the tensile strength was slightly less than that of the L2-AP-i375 specimen. Fig. 12(b) shows the change in the tensile strain at the peak stress and cracked tensile elastic modulus, which was calculated with Eq. (8). Because $0.6 \sigma_{u}$ and $\varepsilon_{@ 0.6 \sigma u}$ in Eq. (8) were in the uncracked stage (i.e., these values did not conform to the definition of cracked tensile modulus of elasticity), the results of the tensile strain at the peak stress and the cracked tensile modulus of elasticity of the L2AP-i500 and L2-AP-i750 specimens in Fig. 12(b) were not comparable. The modulus of elasticity of the L2 specimen was $0.59 \mathrm{GPa}$. However, the modulus of elasticity significantly decreased after 
specimen. The tensile strain at the peak stress in the L2 specimen without anodic polarization was $1.29 \%$, which decreased to $0.84 \%$ in the L2-AP-i 125 specimen and $0.78 \%$ in the L2-AP-i375 specimen. The tensile strains of the carbon-FRCM composites subjected to anodic polarization in the ICCP procedure were less than the design strain of $1.2 \%$ for strengthening provided by ACI 549 [6]. This finding can be explained by a broken bond between the carbon fibre filaments and the mortar matrix. Due to the attack of anodic polarization during ICCP, the outer single filament was not continuously connected to the mortar matrix but had partial connections around its surface, which means that the attack of the anodic polarization during ICCP at the interface between the outer fibres and the surrounding mortar was non-uniform. The local damage in between the carbon fabric mesh and the mortar matrix resulted in a reduction in the tensile strength and strain of the samples [29]. Subsequently, a combination of partially broken bonds and central filament slippage caused the degradation in mechanical properties of the carbon-FRCM composites subjected to anodic polarization during ICCP. charge density increased during the ICCP procedure, as shown in Fig. 13. Although the applied current densities were different for the L2-AP-i500 and L2-AP-i750 specimens, the accumulated charge densities (Eq. (3)) were identical, which could cause the same level of degradation in the tensile strength. A prediction formula indicating a linear reduction in the tensile strength with respect to the accumulated charge density, $q$, was proposed (Eq. (10)), in which $q$ was $10^{6} \mathrm{C} / \mathrm{m}^{2}$.

$$
\sigma_{u}=(-0.33 q+0.99) \sigma_{u_{-} F R C M}
$$


and $2 \mathrm{~mA} / \mathrm{m}^{2}$ for cathodic prevention and between 2 and $20 \mathrm{~mA} / \mathrm{m}^{2}$ for cathodic protection [22]. To investigate the long-term performance of carbon-FRCM as a dual-functional material in ICCP-SS within an acceptable testing time in the laboratory, the adopted current densities of 125, 375, 500 and $750 \mathrm{~mA} / \mathrm{m}^{2}$ in this paper accelerate the ICCP procedure. Research has been conducted to determine the relationship between accelerated tests using a large current density and practical conditions using a small current density. Chang et al. [32] proposed converting the accelerated and practical conditions by the principle of equal cumulative charge, wherein if the cumulative charge in the accelerated and practical conditions are the same, it was assumed that the polarization effects are identical. This relationship has been adopted in many studies for accelerated tests [33,34]. Recently, Zhang et al. [35] reported that a large current density has overestimated effects on the degradation of anode materials. It was concluded that using the principle of equal cumulative charge in accelerated tests will obtain more severe degradation than that from the practical condition $[35,36]$. conducted based on the principle of equal cumulative charge. Taking the L2-AP-i375 specimen into consideration, the total charge density was $15750 \mathrm{~mA} \cdot \mathrm{d} / \mathrm{m}^{2}$. If current densities of 2 and $20 \mathrm{~mA} / \mathrm{m}^{2}$

414 are applied in practical ICCP, the convertible service life could be approximately 22 and 2 years, respectively, which means that the carbon-FRCM could maintain the tensile strength and strain for strengthening when used as an anode in ICCP over a range of 2 to 22 years. In fact, the service life of

417 the dual-functional carbon-FRCM composite could be longer due to overestimated degradation in the accelerated tests. 
420 functional composites. For instance, intermittent ICCP [37] is a useful technique for balancing the

421 efficiency of cathodic protection and the degradation of mechanical properties. Intermittent ICCP is a

kind of strategy of cathodic protection for preventing steel re-bars in concrete from corrosion in which

the protection currents are occasionally rather than continuously applied [38]. The intermittent ICCP

is developed due to the contribution of both the re-alkalization of the steel-concrete interface and

aggressive ions such as chloride away from the steel when ICCP is "on" period. During the ICCP "off"

period, chloride ions present in the concrete disrupt the passive film to accelerate the corrosion reaction,

lower the steel-concrete interfacial $\mathrm{pH}$, and move the steel potential into the corrosion region. Under

these conditions, the corrosion current will increase, eventually requiring the re-application of ICCP

to the rebar. However, Christodoulou et al. [39] found that when ICCP was "off" after five or more

years, the steel re-bars remained passive for another year. Therefore, the effect of successful

application of intermittent ICCP will be a decrease in the average current density for the ICCP system

and as associated increase in the service life of anodes material.

\section{Conclusions}

Carbon-FRCM composites are a promising dual-functional material in ICCP-SS intervention systems, in which these composites can be used for SS and as the anode materials in ICCP systems. The influences of the carbon fabric reinforcement ratio and anodic polarization in ICCP on the tensile behaviour of multiple layers of carbon-FRCM were investigated. The tensile strength, deformation, crack pattern and stiffness based on the stress-strain curves obtained from direct tensile tests were analysed and discussed. From the experimental results, the following conclusions can be drawn:

(1) Increasing the number of fabric layers slightly improved the first cracking stress due to 
441 additional cross-links between the carbon fabric mesh and the short, dispersed carbon fibres in the 442 mortar matrix. Increasing the fabric reinforcement ratio in the carbon-FRCM composites improved 443 the ability of the composites to absorb the energy released during the formation of the first crack in 444 the mortar matrix and mitigated the premature filament failures in carbon fabric mesh reinforcement.

445 (2) The tensile stress-strain behaviours of the carbon-FRCM composites with two layers and four layers of carbon fabric mesh were identical; the maximum tensile strength was $10.03 \mathrm{MPa}$ with respect 447 to the overall cross-sectional area of the carbon-FRCM composites. The reduction in tensile strength and stiffness in the carbon-FRCM composites with one layer of carbon fabric mesh was caused by premature filament failure during crack formation. The typical failure mode of the carbon-FRCM composites with multiple layers of carbon fabric was slippage of the carbon fibre bundles within the mortar matrix.

(3) The macroscopic deterioration of acidification was found around the carbon fabric mesh due to the anodic reactions. The loss of electrical continuity between the carbon fabric mesh and the conductive mortar matrix caused the increases in the feeding voltage and the anode potential.

(4) The local damage between the bonded carbon filaments and the mortar matrix induced by the anodic polarization in ICCP resulted in the degradation of the mechanical properties of the carbonFRCM composites, including the tensile strength, post-cracking stiffness and ultimate tensile strain. In particular, the tensile strength decreased linearly as the accumulated charge density increased in the ICCP procedure.

(5) The long-term effectiveness of ICCP with carbon-FRCM as an anode was verified because the steel rebars were protected cathodically through the accelerated ICCP procedure. The conservative 


\section{Declarations of interest}

None.

\section{Acknowledgements} and the Shenzhen Science and Technology Project (JCYJ20170818094820689).

\section{Data availability statement}

The raw/processed data required to reproduce these findings cannot be shared at this time as the data also forms part of an ongoing study.

\section{References}

[1] Awani O, El-Maaddawy T, Ismail N. Fabric-reinforced cementitious matrix: A promising

[2] Raoof SM, Koutas LN, Bournas DA. Textile-reinforced mortar (TRM) versus fibre-reinforced polymers (FRP) in flexural strengthening of RC beams. Constr Build Mater 2017;151:279-91. D’Ambrisi A, Focacci F. Flexural Strengthening of RC Beams with Cement-Based Composites. J Compos Constr 2011;15:707-20.

[4] Schladitz F, Frenzel M, Ehlig D, Curbach M. Bending load capacity of reinforced concrete slabs strengthened with textile reinforced concrete. Eng Struct 2012;40:317-26.

[5] Hegger J, Voss S. Investigations on the bearing behaviour and application potential of textile reinforced concrete. Eng Struct 2008;30:2050-6.

[6] ACI Committee 549. Guide to Design and Construction of Externally Bonded Fabric-Reinforced 

Structures. American Concrete Institute, 2013.

[7] D'Antino T, Papanicolaou C. Comparison between different tensile test set-ups for the mechanical characterization of inorganic-matrix composites. Constr Build Mater 2018;171:14051.

[8] Carozzi FG, Poggi C. Mechanical properties and debonding strength of Fabric Reinforced Cementitious Matrix (FRCM) systems for masonry strengthening. Compos Part B Eng 2015;70:215-30.

[9] Caggegi C, Lanoye E, Djama K, Bassil A, Gabor A. Tensile behaviour of a basalt TRM strengthening system: Influence of mortar and reinforcing textile ratios. Compos Part B Eng 2017;130:90-102.

[10] Micelli F, Aiello MA. Residual tensile strength of dry and impregnated reinforcement fibres after exposure to alkaline environments. Compos Part B Eng 2019.

[11] De Santis S, Carozzi FG, de Felice G, Poggi C. Test methods for Textile Reinforced Mortar systems. Compos Part B Eng 2017;127:121-32.

[12] Arboleda D, Carozzi FG, Nanni A, Poggi C. Testing Procedures for the Uniaxial Tensile Characterization of Fabric-Reinforced Cementitious Matrix Composites. J Compos Constr 2015;20:04015063.

[13] Donnini J, Corinaldesi V. Mechanical characterization of different FRCM systems for structural reinforcement. Constr Build Mater 2017;145:565-75.

[14] Barhum R, Mechtcherine V. Effect of short, dispersed glass and carbon fibres on the behaviour of textile-reinforced concrete under tensile loading. Eng Fract Mech 2012;92:56-71.

[15] D’Ambrisi A, Focacci F, Luciano R, Alecci V, De Stefano M. Carbon-FRCM materials for structural upgrade of masonry arch road bridges. Compos Part B Eng 2015;75:355-66.

[16] Trapko T, Urbańska D, Kamiński M. Shear strengthening of reinforced concrete beams with PBO-FRCM composites. Compos Part B Eng 2015;80:63-72.

[17] Ebead U, Shrestha KC, Afzal MS, El Refai A, Nanni A. Effectiveness of Fabric-Reinforced Cementitious Matrix in Strengthening Reinforced Concrete Beams. J Compos Constr 2017;21:04016084.

[18] Ombres L, Verre S. Structural behaviour of fabric reinforced cementitious matrix (FRCM) strengthened concrete columns under eccentric loading. Compos Part B Eng 2015;75:235-49.

[19] Babaeidarabad S, Loreto G, Nanni A. Flexural Strengthening of RC Beams with an Externally Bonded Fabric-Reinforced Cementitious Matrix. J Compos Constr 2014;18:04014009.

[20] Yin SP, Peng C, Jin ZY. Research on Mechanical Properties of Axial-Compressive Concrete Columns Strengthened with TRC under a Conventional and Chloride Wet-Dry Cycle Environment. J Compos Constr 2017;21:04016061.

[21] Bertolini L, Bolzoni F, Pedeferri P, Lazzari L, Pastore T. Cathodic protection and cathodic prevention in concrete: Principles and applications. J Appl Electrochem 1998;28:1321-31.

[22] Pedeferri P. Cathodic protection and cathodic prevention. Constr Build Mater 1996;10:391-402.

[23] Zhu JH, Su MN, Huang JY, Ueda T, Xing F. The ICCP-SS technique for retrofitting reinforced concrete compressive members subjected to corrosion. Constr Build Mater 2018;167:669-79.

[24] Su MN, Wei LL, Zeng ZW, Ueda T, Xing F, Zhu JH. A solution for sea-sand reinforced concrete beams. Constr Build Mater 2019;204:586-96. 
[25] Van Nguyen C, Mangat P, Jones G, O'Flaherty F, Lambert P. The Performance of Carbon Fibre Composites as ICCP Anodes for Reinforced Concrete Structures. ISRN Corros 2012;2012.

[26] British Standards Institution. Methods of testing cement — Part 1: Determination of strength. 1995.

[27] ASTM D4018. Standard Test Methods for Properties of Continuous Filament Carbon and Graphite Fiber Tows. 1999.

[28] ICC-ES AC434. Acceptance criteria for masonry and concrete strengthening using fabricreinforced cementitious matrix (FRCM) and steel reinforced grout (SRG) composite systems. ICC Evaluation Service, 2016.

[29] Häußler-Combe U, Hartig J. Bond and failure mechanisms of textile reinforced concrete (TRC) under uniaxial tensile loading. Cem Concr Compos 2007;29:279-89.

[30] BS EN 12696. Cathodic protection of steel in concrete. European Committee for Standardization; 2016.

[31] Bertolini L, Bolzoni F, Pastore T, Pedeferri P. Effectiveness of a conductive cementitious mortar anode for cathodic protection of steel in concrete. Cem Concr Res 2004;34:681-94.

[32] Chang JJ, Yeih W, Huang R. Degradation of the bond strength between rebar and concrete due to the impressed cathodic current. J Mar Sci Technol 1999;7:89-93.

[33] Anwar MS, Sujitha B, Vedalakshmi R. Light-weight cementitious conductive anode for impressed current cathodic protection of steel reinforced concrete application. Constr Build Mater 2014;71:167-80.

[34] Cramer SD, Covino Jr BS, Bullard SJ, Holcomb GR, Russell JH, Nelson FJ, Laylor HM, Soltesz SM. Corrosion prevention and remediation strategies for reinforced concrete coastal bridges. Cem Concr Compos 2002;24:101-17.

[35] Zhang E, Abbas Z, Tang L. Predicting degradation of the anode-concrete interface for impressed current cathodic protection in concrete. Constr Build Mater 2018;185:57-68.

[36] Zhang EQ, Tang L, Zack T. Carbon Fiber as Anode Material for Cathodic Prevention in Cementitious Materials. 5th Int. Conf. Durab. Concr. Struct., Shenzhen, Guangdong Province, P.R.China: 2016.

[37] Glass GK, Hassanein AM, Buenfeld NR. Cathodic protection afforded by an intermittent current applied to reinforced concrete. Corros Sci 2001;43:1111-31.

[38] Byrne A, Holmes N, Norton B. State-of-the-art review of cathodic protection for reinforced concrete structures. Mag Concrete Res 2016;68(13):664-77.

[39] Christodoulou C, Glass G, Webb J, Austin S, Goodier C. Assessing the long-term benefits of Impressed Current Cathodic Protection. Corros Sci 2010;52(8):2671-79. 


\section{Figure Captions:}

Fig. 1. Dimensions of the carbon fabric mesh for preparing carbon-FRCM composites.

Fig. 2. Preparation of carbon-FRCM panels (units: mm).

Fig. 3. A simulated ICCP setup for carbon-FRCM composites.

Fig. 4. Tensile tests of carbon-FRCM coupons: (a) preparation of carbon-FRCM coupons for the tensile tests; (b) tensile tests setup.

Fig. 5. Stress-strain behaviour of the carbon-FRCM coupons for two different evaluations: (a) the cross-sectional area of the carbon fabric mesh; (b) the entire cross-sectional area of the composite.

Fig. 6. Typical stress-strain relation of the FRCM composites.

Fig. 7. Typical slippage failure mode of the carbon-FRCM composites.

Fig. 8. Critical points in the stress-strain curves obtained from the direct tensile tests: (a) cracked stage; (b) crack development stage.

Fig. 9. Feeding voltage $\left(\boldsymbol{\varpi}, E_{f e e d}\right)$, anode potential $\left(\boldsymbol{\Delta}, E_{a n}\right)$ and steel potential $\left(\circ, E_{c a t}\right)$ in the ICCP procedure: (a) L2-AP-i125; (b) L2-AP-i375; (c) L2-AP-i500; (d) L2-AP-i750.

Fig. 10. Acidification detection around the carbon fabric mesh.

Fig. 11. Stress-strain behaviour of the carbon-FRCM composites subjected to anodic polarization in the ICCP procedure.

Fig. 12. Effect of current density on the tensile strength, maximum strain and cracked tensile elastic modulus: (a) tensile strength; (b) maximum strain and cracked tensile elastic modulus.

Fig. 13. Prediction of the tensile strength as a function of the accumulated charge density. 


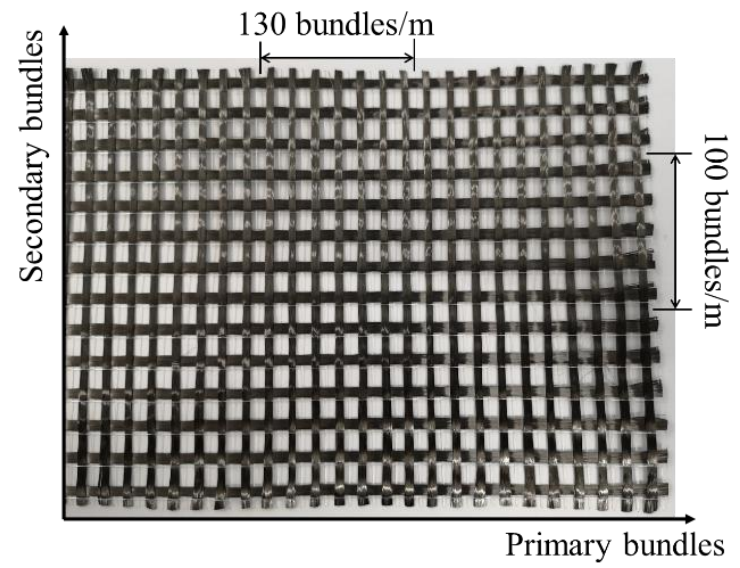

Fig. 1. Dimensions of the carbon fabric mesh for preparing carbon-FRCM composites.

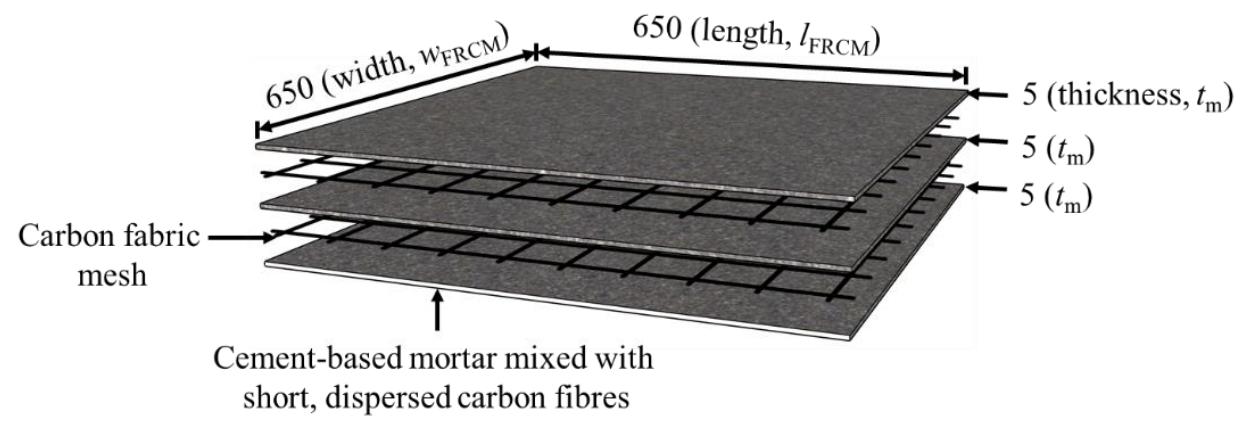

Fig. 2. Preparation of carbon-FRCM panels $\left(w_{\mathrm{FRCM}}=\right.$ width of $\mathrm{FRCM}$ panel; $l_{\mathrm{FRCM}}=$ length of

FRCM panel; $t_{\mathrm{m}}=$ thickness of each layer of cementitious mortar matrix. units: $\mathrm{mm}$ ). 


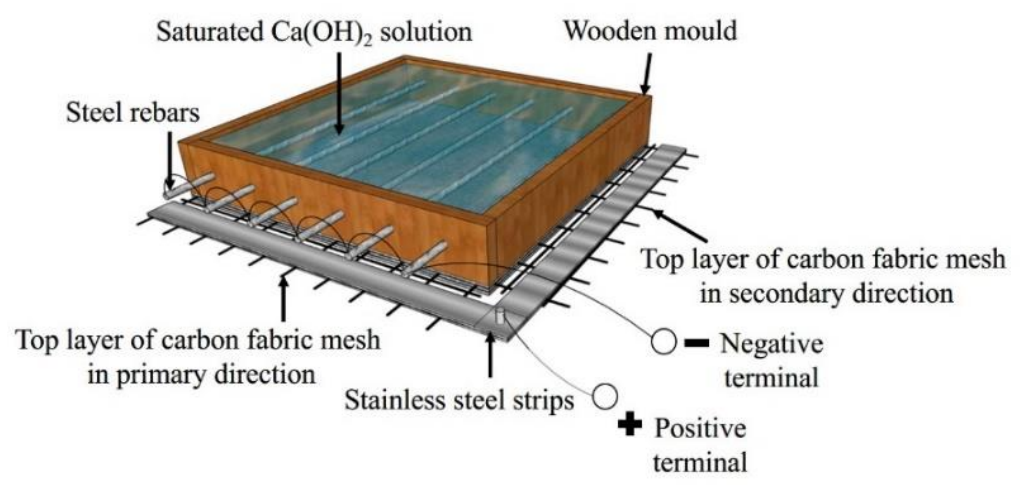

Fig. 3. A simulated ICCP setup for carbon-FRCM composites.

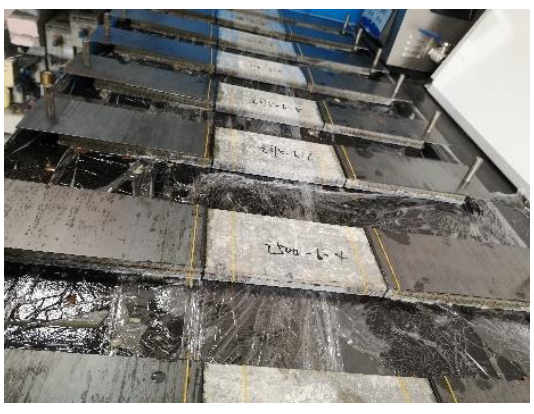

(a)

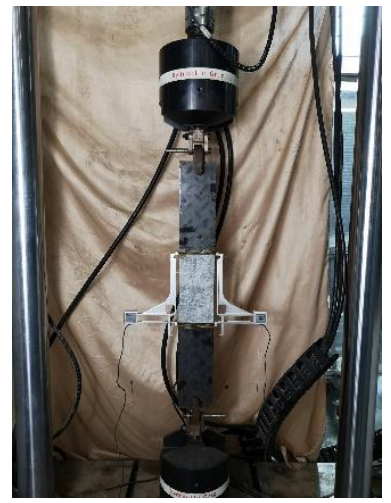

(b)

Fig. 4. Tensile tests of carbon-FRCM coupons: (a) preparation of carbon-FRCM coupons for the

tensile tests; (b) tensile tests setup. 


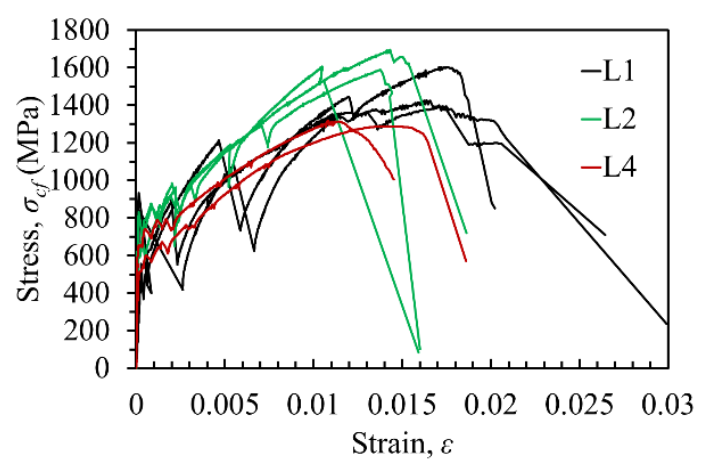

(a)

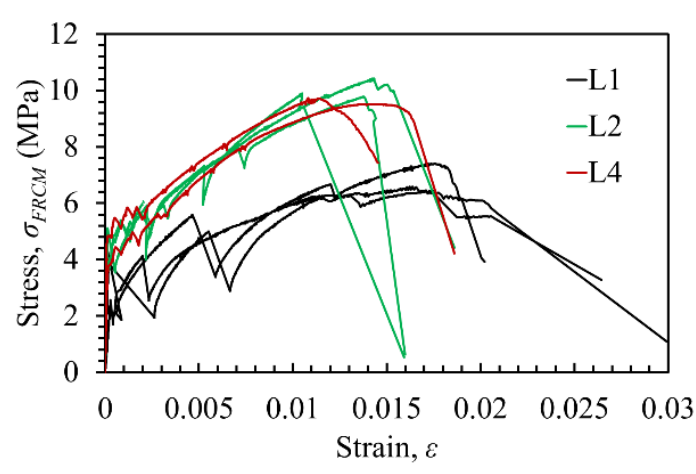

(b)

Fig. 5. Stress-strain behaviour of the carbon-FRCM coupons under different evaluations: (a) the cross-sectional area of the carbon fabric mesh; (b) the entire cross-sectional area of the composite.

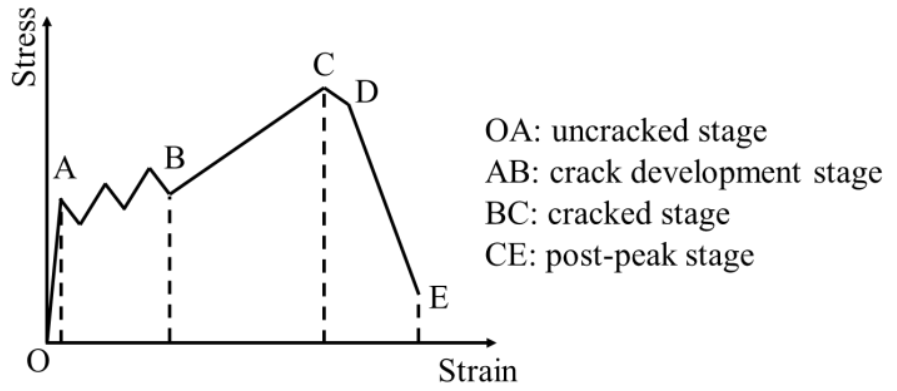

Fig. 6. Typical stress-strain relation of the FRCM composites [28]. 


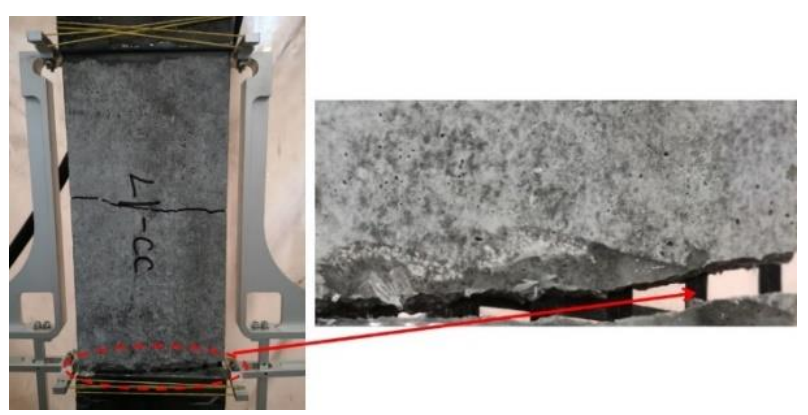

Fig. 7. Typical slippage failure mode of the carbon-FRCM composites.

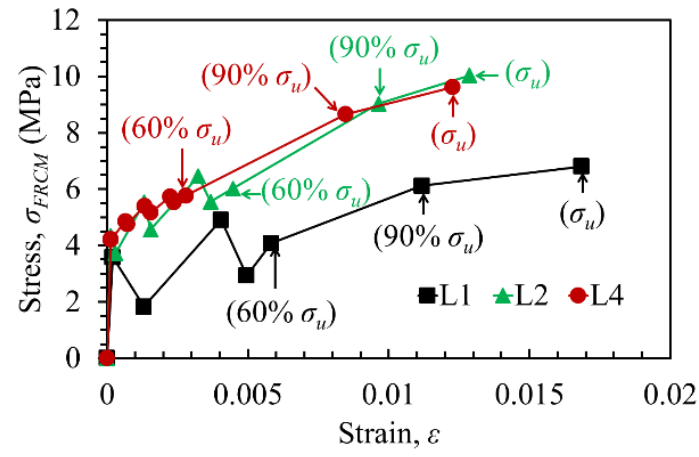

(a)

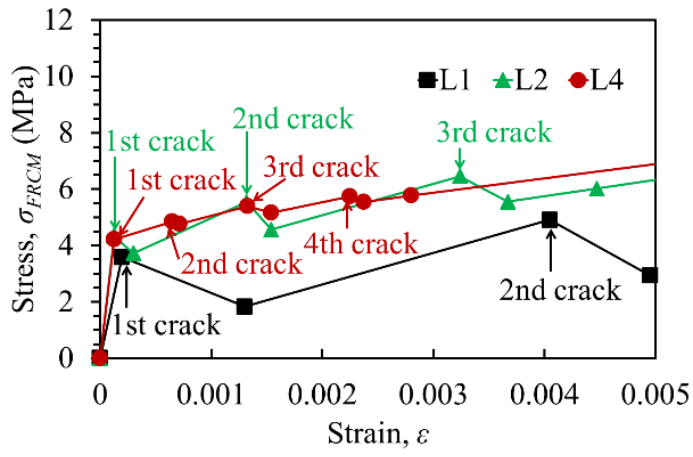

(b)

Fig. 8. Critical points in the stress-strain curves obtained from the direct tensile tests: (a) cracked stage; (b) crack development stage. 


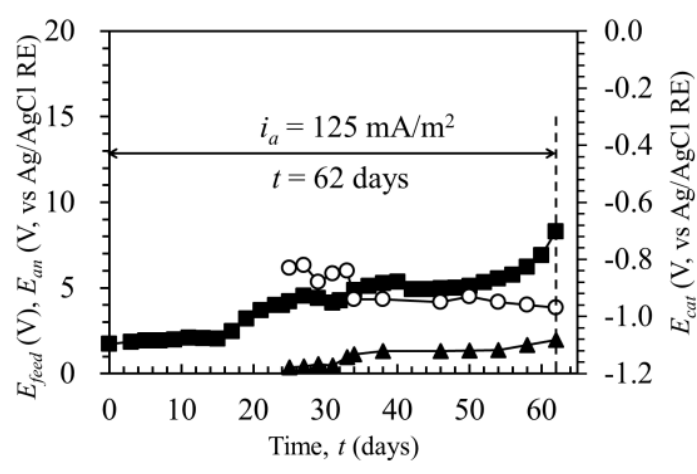

(a)

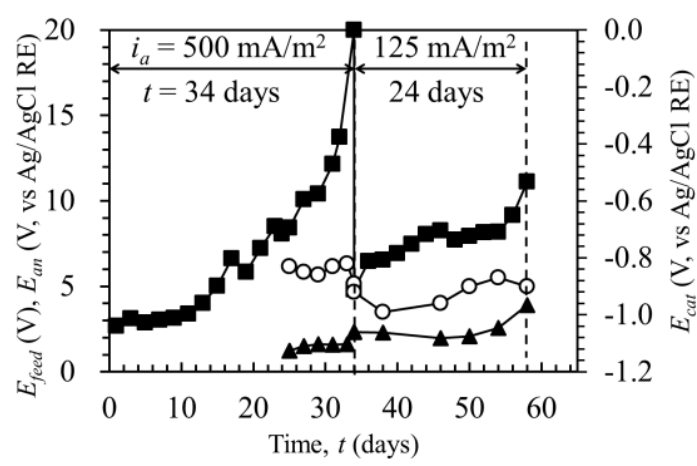

(c)

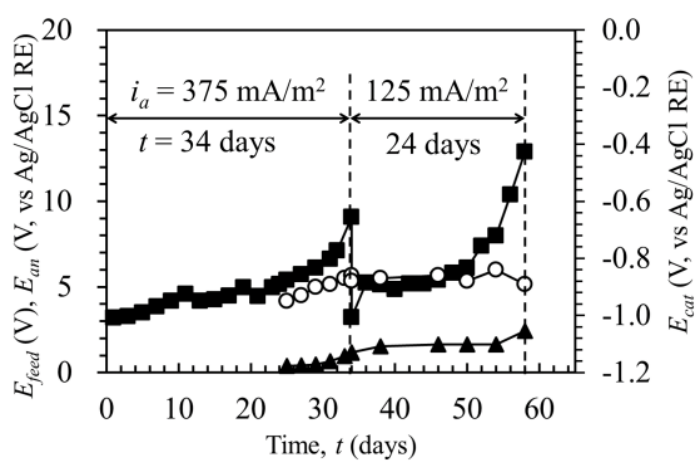

(b)

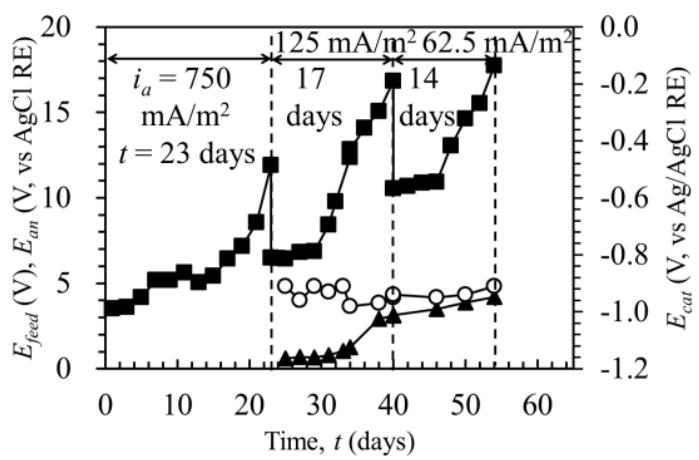

(d)

Fig. 9. Feeding voltage $\left(\mathbf{-}, E_{\text {feed }}\right)$, anode potential $\left(\boldsymbol{\Lambda}, E_{\text {an }}\right)$ and steel potential $\left(\circ, E_{c a t}\right)$ in the ICCP procedure: (a) L2-AP-i125; (b) L2-AP-i375; (c) L2-AP-i500; (d) L2-AP-i750. 


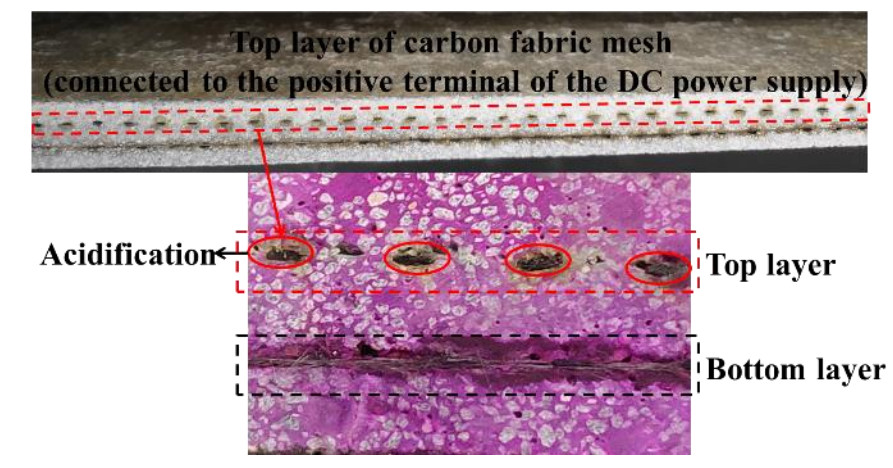

Fig. 10. Acidification detection around the carbon fabric mesh.

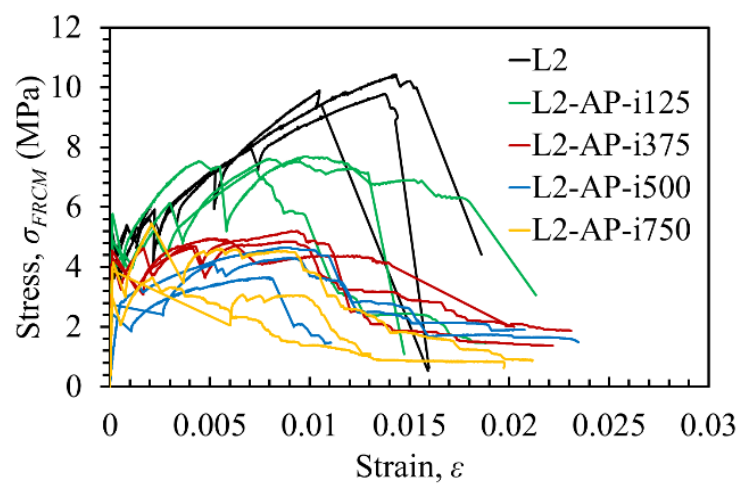

Fig. 11. Stress-strain behaviour of the carbon-FRCM composites subjected to anodic polarization in the ICCP procedure. 

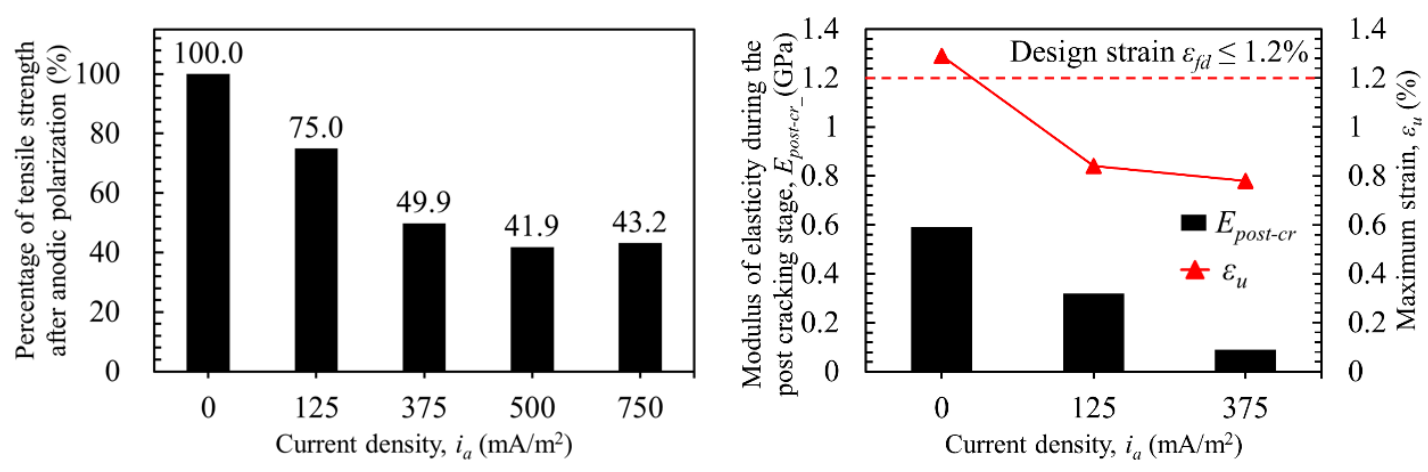

Fig. 12. Effect of current density on the tensile strength, maximum strain and cracked tensile elastic modulus: (a) tensile strength; (b) maximum strain and cracked tensile elastic modulus.

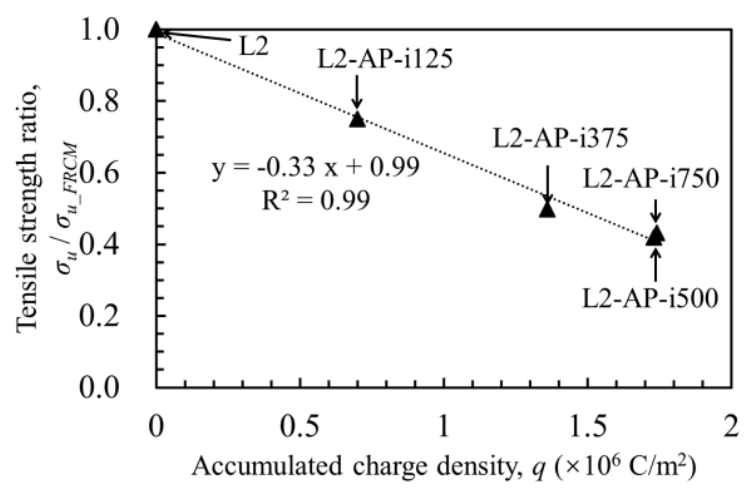

Fig. 13. Prediction of tensile strength as a function of the accumulated charge density. 
Table 1

Cement-based mortar composition (units: $\mathrm{kg} / \mathrm{m}^{3}$ ).

\begin{tabular}{cccccc}
\hline \multirow{2}{*}{ Cement } & \multirow{2}{*}{ Water } & \multicolumn{2}{c}{ Quartz sand } & \multirow{2}{*}{ Superplasticizer } & Short carbon fibres \\
\cline { 3 - 4 } & & Fine size & Moderate size & & \\
\hline 851 & 298 & 284 & 567 & 0.85 & 6.38 \\
\hline
\end{tabular}

Table 2

Tensile properties of carbon fibres.

\begin{tabular}{ccccc}
\hline Carbon fibres & $\begin{array}{c}\text { Tensile strength } \\
(\mathrm{MPa})\end{array}$ & $\begin{array}{c}\text { Elastic modulus } \\
(\mathrm{GPa})\end{array}$ & $\begin{array}{c}\text { Strain-to- } \\
\text { failure }(\%)\end{array}$ & $\begin{array}{c}\text { Nominal cross- } \\
\text { sectional area } \\
\left(\mathrm{mm}^{2}\right)\end{array}$ \\
\hline Fibre filament $^{*}$ & 4900 & 230 & 2.1 & $3.85 \times 10^{-5}$ \\
Fibre bundle $^{\#}$ & 2125 & 196.4 & 1.1 & 0.462 \\
\hline
\end{tabular}

Note: * represents the tensile properties of the carbon fibre filament provided by the manufacturer; \# represents the tensile properties of the dry carbon fibre bundle obtained from the direct tensile tests conducted by the authors.

\section{Table 3}

Test parameters of the carbon-FRCM coupons.

\begin{tabular}{|c|c|c|c|c|c|c|c|}
\hline \multirow[b]{2}{*}{ Series } & \multirow[b]{2}{*}{$\begin{array}{l}\text { Carbon- } \\
\text { FRCM } \\
\text { coupons }\end{array}$} & \multirow{2}{*}{$\begin{array}{c}\text { Layers } \\
\text { of } \\
\text { carbon } \\
\text { fabric } \\
\text { mesh }\end{array}$} & \multirow[b]{2}{*}{$\begin{array}{c}\text { Fabric } \\
\text { reinforcement } \\
\text { ratio } \\
\left(\rho_{c f m}, \%\right)\end{array}$} & \multicolumn{3}{|c|}{ Anodic polarization } & \multirow[b]{2}{*}{$\begin{array}{c}\text { Number } \\
\text { of test } \\
\text { coupons }\end{array}$} \\
\hline & & & & $\begin{array}{c}\text { Current } \\
\text { density } \\
\left(i_{a}, \mathrm{~mA} / \mathrm{m}^{2}\right)\end{array}$ & $\begin{array}{c}\text { Duration } \\
(t, \text { days })\end{array}$ & $\begin{array}{l}\text { Accumulated } \\
\text { charge density } \\
\left(q, \times 10^{6} \mathrm{C} / \mathrm{m}^{2}\right)\end{array}$ & \\
\hline \multirow{3}{*}{ I } & L1 & 1 & 0.462 & & N/A & & 3 \\
\hline & L2 & 2 & 0.615 & & N/A & & 3 \\
\hline & L4 & 4 & 0.739 & & N/A & & 3 \\
\hline \multirow{4}{*}{ II } & L2-AP-i125 & 2 & 0.615 & 125 & 62 & 0.70 & 3 \\
\hline & L2-AP-i375 & 2 & 0.615 & $375 / 125$ & $34 / 24$ & 1.36 & 3 \\
\hline & L2-AP-i500 & 2 & 0.615 & $500 / 125$ & $34 / 24$ & 1.73 & 3 \\
\hline & L2-AP-i750 & 2 & 0.615 & $750 / 125 / 62.5$ & $23 / 17 / 14$ & 1.74 & 3 \\
\hline
\end{tabular}


Table 4

Average tensile testing results of the carbon-FRCM composites in series I and II.

\begin{tabular}{|c|c|c|c|c|c|c|c|c|c|c|c|}
\hline \multirow{2}{*}{ Specimens } & \multirow{2}{*}{$\begin{array}{c}\text { Data } \\
\text { analysis }\end{array}$} & \multirow{2}{*}{$F_{u}(\mathrm{kN})$} & \multirow{2}{*}{$\varepsilon_{u}(\%)$} & \multicolumn{4}{|c|}{$\begin{array}{l}\text { Regarding the carbon fabric mesh } \\
\text { (Eq. (4)) }\end{array}$} & \multicolumn{4}{|c|}{$\begin{array}{l}\text { Regarding the carbon-FRCM composite } \\
\text { (Eq. (6)) }\end{array}$} \\
\hline & & & & $\begin{array}{c}\sigma_{c r} \\
(\mathrm{MPa})\end{array}$ & $\begin{array}{l}E_{\text {pre-cr }} \\
(\mathrm{GPa})\end{array}$ & $\begin{array}{c}\sigma_{u} \\
(\mathrm{MPa})\end{array}$ & $\begin{array}{l}E_{\text {post-cr }} \\
(\mathrm{GPa})\end{array}$ & $\begin{array}{c}\sigma_{c r} \\
(\mathrm{MPa})\end{array}$ & $E_{\text {pre-cr }}(\mathrm{GPa})$ & $\begin{array}{c}\sigma_{u} \\
(\mathrm{MPa})\end{array}$ & $E_{\text {post-cr }}(\mathrm{GPa})$ \\
\hline \multirow{2}{*}{$\mathrm{L} 1$} & Average & 6.81 & 1.69 & 776 & 4557 & 1474 & 92.4 & 3.59 & 21.0 & 6.81 & 0.42 \\
\hline & Cov & 0.08 & 0.02 & 0.25 & 0.54 & 0.08 & 0.42 & 0.25 & 0.54 & 0.08 & 0.43 \\
\hline \multirow{2}{*}{$\mathrm{L} 2$} & Average & 15.05 & 1.29 & 705 & 5656 & 1630 & 77.3 & 4.34 & 34.8 & 10.03 & 0.59 \\
\hline & Cov & 0.04 & 0.16 & 0.16 & 0.15 & 0.03 & 0.15 & 0.16 & 0.15 & 0.03 & 0.44 \\
\hline \multirow{2}{*}{ L4 } & Average & 24.05 & 1.23 & 572 & 4619 & 1303 & 69.0 & 4.22 & 34.2 & 9.62 & 0.51 \\
\hline & Cov & 0.02 & 0.17 & 0.19 & 0.38 & 0.02 & 0.02 & 0.19 & 0.38 & 0.02 & 0.02 \\
\hline \multirow{2}{*}{ L2-AP-i125 } & Average & 11.28 & 0.84 & 808 & 6202 & 1222 & 52.1 & 4.97 & 39.9 & 7.52 & 0.32 \\
\hline & Cov & 0.03 & 0.15 & 0.15 & 0.16 & 0.03 & 0.35 & 0.15 & 0.15 & 0.03 & 0.34 \\
\hline \multirow{2}{*}{ L2-AP-i375 } & Average & 7.50 & 0.78 & 710 & 6348 & 813 & 14.1 & 4.37 & 37.1 & 5.00 & 0.09 \\
\hline & Cov & 0.04 & 0.28 & 0.04 & 0.13 & 0.04 & 0.52 & 0.04 & 0.15 & 0.04 & 0.44 \\
\hline \multirow{2}{*}{ L2-AP-i500 } & Average & 6.31 & 0.85 & 434 & 3123 & 683 & 1 & 2.67 & 19.2 & 4.20 & / \\
\hline & Cov & 0.12 & 0.07 & 0.08 & 0.83 & 0.12 & 1 & 0.08 & 0.83 & 0.12 & 1 \\
\hline \multirow{2}{*}{ L2-AP-i750 } & Average & 6.50 & 0.14 & 596 & 4806 & 704 & I & 3.67 & 29.58 & 4.33 & I \\
\hline & Cov & 0.23 & 0.86 & 0.17 & 0.28 & 0.23 & 1 & 0.17 & 0.28 & 0.23 & 1 \\
\hline
\end{tabular}

